\title{
Effects of lipase inhibition on gastric emptying and alcohol absorption in healthy subjects
}

\author{
Reawika Chaikomin, Antonietta Russo, Christopher K. Rayner, Christine Feinle-Bisset, \\ Deirdre G. O’Donovan, Michael Horowitz and Karen L. Jones* \\ Discipline of Medicine, University of Adelaide, Royal Adelaide Hospital, North Terrace Adelaide, \\ South Australia, Australia, 5000
}

(Received 26 February 2006 - Revised 6 July 2006 - Accepted 7 July 2006)

\begin{abstract}
The rate of alcohol absorption is dependent on gastric emptying (GE). As the slowing of GE by fat is dependent on lipolysis, orlistat may increase the rise in blood alcohol when alcohol is consumed with, or after, fat. The aim of the study was to evaluate the effects of orlistat on GE and blood alcohol after an alcohol-containing drink following a fat 'preload', in healthy subjects. Ten healthy males consumed $120 \mathrm{ml}$ cream with or without $120 \mathrm{mg}$ orlistat, $30 \mathrm{~min}$ before an alcohol-containing drink labelled with $20 \mathrm{MBq}\left[{ }^{99 \mathrm{~m}} \mathrm{Tc}\right]$ sulfur colloid on $2 \mathrm{~d}$. GE, plasma alcohol and blood glucose were measured. GE was slightly faster with orlistat $(P<0.05)$ compared with control. Plasma alcohol at 15 min was slightly higher with orlistat $(0.034$ (SEM 0.006) $\mathrm{g} / 100 \mathrm{ml}) v$. control $(0.029$ (SEM 0.005) $\mathrm{g} / 100 \mathrm{ml})(P<0.05)$, but there was no effect on the area under the curve $0-240 \mathrm{~min}$. The increase in blood glucose was greater with orlistat, for example, at $15 \mathrm{~min}(1.07$ (SEM 0.2$) \mathrm{mmol} / \mathrm{l}) \mathrm{v}$. control $(0.75$ (SEM $0 \cdot 2) \mathrm{mmol} / \mathrm{l})(P=0.05)$. The rise in blood glucose and plasma alcohol were related (for example, at $15 \mathrm{~min} r 0.49 ; P=0.03)$. In conclusion, lipase inhibition accelerates GE of an alcohol-containing drink following a fat 'preload' with a minor increase in the initial rise in plasma alcohol
\end{abstract}

Gastric emptying: Orlistat: Plasma alcohol: Blood glucose

The rate of gastric emptying is regulated primarily by feedback inhibition generated by the interaction of nutrients with the small intestine (Hunt et al. 1985; Lin et al. 1989; Borovicka et al. 2000; Rayner et al. 2001); the magnitude of this feedback is dependent on the length of small intestine exposed (Lin et al. 1989). Of the three macronutrients, fat is the most potent in slowing gastric emptying, primarily because of its higher energy density, and potentially also because its absorption rate is relatively slower (Lin et al. 1996). Accordingly, consumption of fat before, or with, a meal slows gastric emptying (Cunningham \& Read, 1989; Stacher et al. 1990, 1991; Davidson et al. 1999), and delays the absorption of orally administered nutrients (Welch et al. 1987; Cunningham \& Read, 1989; Hebbard et al. 1995). For example, when lipid is infused directly into the small intestine before the consumption of, or incorporated into, a carbohydrate-containing (potato) meal, the glycaemic response to that meal is substantially less (Welch et al. 1987; Cunningham \& Read, 1989). Fat appears to be most potent in slowing gastric emptying when given before, rather than with, a meal (Cunningham \& Read, 1989). This is to be expected; it takes some time for smallintestinal feedback mechanisms induced by fat to become established (Feinle et al. 2003), and administration of fat before a meal ensures that it would empty preferentially and be partially digested in the small intestine before the meal is consumed.
Like most drugs, alcohol is absorbed predominantly from the small intestine; hence, pharmacological (Nimmo, 1976; Johnson et al. 1991) or dietary (Horowitz et al. 1989; Hebbard et al. 1995) factors that modify gastric emptying may affect the rate of alcohol absorption (Holt, 1981). In particular, interventions that slow gastric emptying have the potential to minimise the rise in blood alcohol concentrations, mainly by decreasing the access of alcohol to the small-intestinal mucosa and, possibly, by increasing 'first-pass' alcohol metabolism by the liver and, possibly, the stomach (DiPadova et al. 1987; Caballeria et al. 1989; Frezza et al. 1990). Anecdotal evidence that ingestion of fat (for example, olive oil) before the consumption of alcohol may reduce inebriation is consistent with this concept.

The lipase inhibitor, orlistat, is now used widely in the treatment of obesity. As a result of inhibition of gastric and pancreatic lipase, orlistat, when given in a dose of $120 \mathrm{mg}$ with a meal, reduces dietary fat absorption by about $40 \%$ (Davidson et al. 1999). We have recently reported, in patients with type 2 diabetes managed by diet, that acute administration of orlistat potentiates the initial postprandial rise in blood glucose after both an oil or aqueous drink containing glucose (Pilichiewicz et al. 2003) and a high-fat, mashed potato, meal (O'Donovan et al. 2004a). These observations were not surprising, given that the slowing of gastric emptying by fat is dependent on lipolysis (Carney et al. 1995; 
Schwizer et al. 1997; Borovicka et al. 2000), i.e. NEFA are responsible for mediating small-intestinal feedback inhibition (Feinle et al. 2003), and the rate of gastric emptying is a major determinant of the glycaemic response to carbohydrate-containing meals (Horowitz et al. 1993a; Jones et al. 1996; Rayner et al. 2001). Accordingly, we reasoned that orlistat has the potential to increase the magnitude of the rise in blood alcohol when an alcohol-containing beverage is consumed with fat, and that these effects were likely to be most marked when fat was consumed before the alcohol. Perhaps surprisingly, this concept has not been evaluated previouslyone study reported that orlistat had no effect on alcohol absorption, but the drink contained carbohydrate only (Melia et al. 1998).

We have now evaluated the effects of lipase inhibition on gastric emptying and blood alcohol and glucose concentrations after ingestion of an alcohol-containing drink consumed after a fat 'preload', in healthy subjects.

\section{Materials and methods}

\section{Subjects}

Ten healthy adult males (age 29.5 (SE 3.7) years; BMI 23.1 (SE 0.8$) \mathrm{kg} / \mathrm{m}^{2}$ ) were recruited by advertisement. No subject had a history of gastrointestinal disease or surgery, significant respiratory or cardiac disease, alcohol abuse, or epilepsy and none smoked more than ten cigarettes per d, or was taking medication known to affect gastrointestinal function. The protocol was approved by the Research Ethics Committee of the Royal Adelaide Hospital, and each subject gave written, informed consent.

\section{Protocol}

Each subject was studied on two occasions, separated by an interval of $4-7 \mathrm{~d}$ in randomised, single-blind order. Each study commenced at 08.30 hours, following an overnight fast (14h for solids, $12 \mathrm{~h}$ for liquids), when an intravenous cannula was inserted into an antecubital vein for blood sampling. On both days, subjects consumed $120 \mathrm{ml}$ full-fat cream (Bulla Thick cream; Bulla Dairy Foods, Derrimut, Victoria, Australia; carbohydrate $55.3 \mathrm{~kJ}$ (13.2 kcal), fat $1398 \mathrm{~kJ}(333.9 \mathrm{kcal})$, protein $44.4 \mathrm{~kJ}(10.6 \mathrm{kcal}))$ with or without $120 \mathrm{mg}$ orlistat (Xenical ${ }^{\mathrm{TM}}$; Roche Products Pty., Dee Why, NSW, Australia), which was mixed thoroughly into the cream, $30 \mathrm{~min}$ before consuming a $230 \mathrm{ml}$ drink comprising $97 \mathrm{ml}$ 'Feel Good' iced chocolate (Farmers Union; National Foods Limited, Melbourne, Victoria, Australia; carbohydrate $94.6 \mathrm{~kJ} \quad(22.6 \mathrm{kcal})$, fat $19.3 \mathrm{~kJ}$ (4.6 kcal), protein $82.9 \mathrm{~kJ}(19.8 \mathrm{kcal}))$, low-energy sweetener (SPLENDA ${ }^{\circledR}$; Johnson and Johnson Pacific, Broadway, NSW, Australia; carbohydrate $77.9 \mathrm{~kJ}$ (18.6 kcal) and $66.5 \mathrm{ml}$ vodka (Premium Vodka 2000 Millennium product; Wyborowa SA Poznan, Poland; $20 \mathrm{~g}$ alcohol; $334.9 \mathrm{~kJ}$ $(80 \mathrm{kcal}))$ and $66.5 \mathrm{ml}$ water labelled with $20 \mathrm{MBq}$ $\left[{ }^{99 \mathrm{~m}} \mathrm{Tc}\right]$ sulfur colloid, while sitting in front of a $\gamma$ camera (Collins et al. 1983; Horowitz et al. 1989; Johnson et al. 1991). Accordingly, the energy content of the cream 'preload' was $1497.6 \mathrm{~kJ}(357.7 \mathrm{kcal})$ and the drink contained $606.2 \mathrm{~kJ}(144.8 \mathrm{kcal})$, i.e. total energy $2103.9 \mathrm{~kJ}(502.5 \mathrm{kcal})$.
The drink was consumed over $5 \mathrm{~min}$, and radioisotopic data were acquired between 0 and $240 \mathrm{~min}(60 \mathrm{~s}$ frames for the first $60 \mathrm{~min}$, $3 \mathrm{~min}$ frames thereafter, with time 0 (t $0 \mathrm{~min}$ ) defined as the time of completion of the drink. Venous blood samples $(5-10 \mathrm{ml}$ in volume) were collected at $\mathrm{t}$ $-5,15,30,45,60,75,90,105,120,150,180,210$ and $240 \mathrm{~min}$. Blood glucose was measured on all of the samples; plasma alcohol was measured on the samples obtained at $t$ $-5,15,30,60,90,120,150$ and $240 \mathrm{~min}$. Subjects were allowed to leave the laboratory after $5 \mathrm{~h}$ and were asked to record any gastrointestinal symptoms and their bowel habit over the following $48 \mathrm{~h}$.

\section{Measurements}

Gastric emptying. Data were corrected for subject movement, radionuclide decay and $\gamma$-ray attenuation (Collins et al. 1983; Pilichiewicz et al. 2003). Gastric emptying curves were derived by drawing a region-of-interest around the total stomach, from which the intragastric content at t $0,15,30$, $45,60,75,90,120,150,180$ and $240 \mathrm{~min}$ and the $50 \%$ gastric emptying time were calculated (Collins et al. 1983).

Blood glucose and plasma alcohol concentrations. Blood glucose concentrations were determined immediately using a portable glucose meter (Medisense Precision QID; Abbott Laboratories, Bedford, MA, USA). The accuracy of this method has been confirmed in our laboratory using the hexokinase technique (Horowitz et al. 1996). The maximum increase in blood glucose from baseline (i.e. $\mathrm{t}-5 \mathrm{~min}$ ), and the areas under the curve (AUC) for the change in blood glucose between -5 to $30 \mathrm{~min}$, -5 to $60 \mathrm{~min}$ and -5 to $240 \mathrm{~min}$, were calculated. Blood samples for determination of plasma alcohol were collected in ice-chilled tubes. Plasma was separated by centrifugation and stored at $-70^{\circ} \mathrm{C}$ for subsequent analysis by chromatography (Cooper, 1971). The maximum increase in blood alcohol from baseline, and the AUC between -5 to $30 \mathrm{~min},-5$ to $60 \mathrm{~min}$ and -5 to $240 \mathrm{~min}$, were calculated.

\section{Statistical analysis}

Data were evaluated using repeated-measures ANOVA and are presented as means with their standard errors. Mean contrasts were used to analyse individual point-by-point comparisons. AUC for blood glucose and plasma alcohol were calculated using the trapezoidal rule and compared using Student's paired $t$ test. Relationships between gastric emptying and the early rise in blood glucose and plasma alcohol concentrations were assessed using linear regression analysis. $P<0.05$ was considered significant in all analyses.

\section{Results}

All subjects tolerated the study well; two subjects reported loose bowel actions after orlistat - in both cases the symptoms were mild and resolved within $48 \mathrm{~h}$. All subjects experienced no gastrointestinal symptoms.

\section{Gastric emptying}

Gastric emptying was faster with orlistat $(P<0.05)$ when compared with the drink without orlistat (Fig. 1(a)), although 

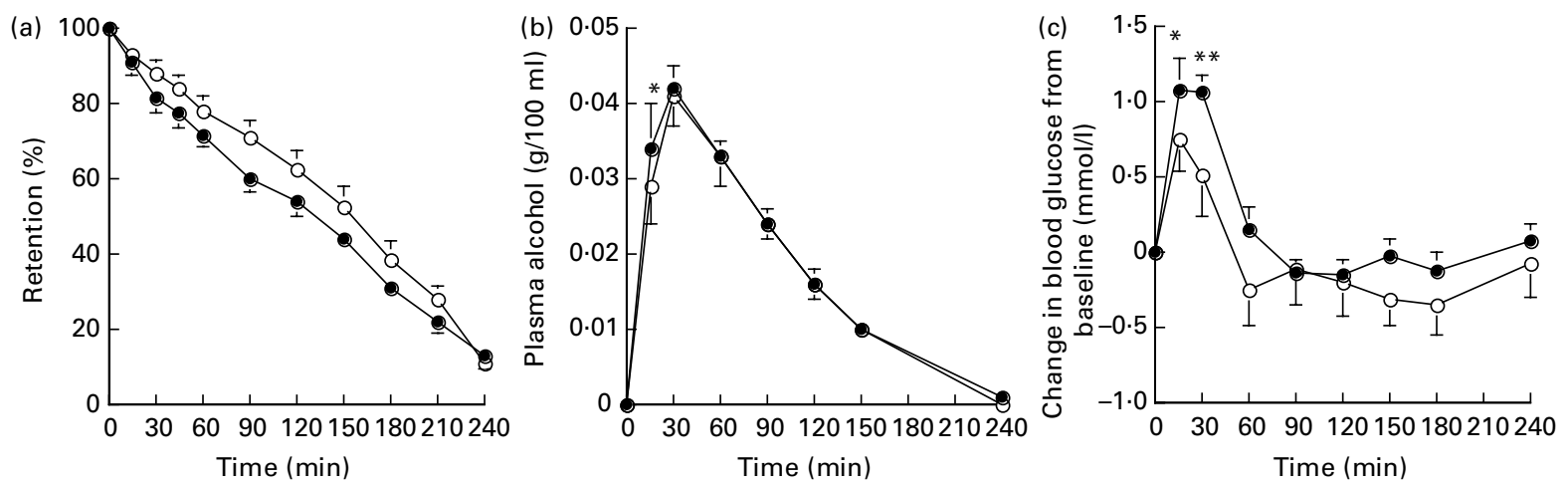

Fig. 1. (a) Gastric emptying, (b) plasma alcohol and (c) blood glucose concentrations in response to a drink containing $20 \mathrm{~g}$ alcohol, consumed 30 min after ingestion of $120 \mathrm{ml}$ cream with $\left(-\mathbf{O}_{-}^{-}\right)$or without $\left(-\mathrm{O}_{-}\right.$; control) orlistat. Data are means, with their standard errors represented by vertical bars. Mean value was significantly different from that of control: ${ }^{\star} P<0.05,{ }^{*} P=0.001$. The presence of orlistat had a significant effect on gastric emptying (ANOVA); $P<0.05$. For details of subjects and procedures, see p. 884

there was no significant difference in the $50 \%$ gastric emptying time (orlistat $102 \cdot 8$ (SEM 8.3) min $v$. control 116.0 (SEM 10.9) $\mathrm{min}$ ).

\section{Plasma alcohol and blood glucose concentrations}

Plasma alcohol concentrations increased after the drinks on both study days $(P<0 \cdot 05)$. The plasma alcohol concentration at $\mathrm{t} 15 \mathrm{~min}$ was slightly higher with orlistat (orlistat 0.034 (SEM 0.006) g/100 ml $v$. control 0.029 (SEM 0.005) g/100 ml; $P<0.05)$. There was no overall difference in plasma alcohol concentrations $(P=0.65)$, or peak blood alcohol (orlistat 0.045 (SEM 0.003) g/100 ml v. control 0.044 (SEM 0.004) $\mathrm{g} / 100 \mathrm{ml}$ ) between the two study days (Fig. 1(b)). There was no significant difference between orlistat and control in the AUC between -5 to $30 \mathrm{~min}$ (orlistat $0.82 \quad(\mathrm{SEM} 0 \cdot 11$ ) $\mathrm{g} / 100 \mathrm{ml} \times \min v$. control $0.74(\operatorname{SEM} 0.10) \mathrm{g} / 100 \mathrm{ml} \times \mathrm{min}$, -5 to $60 \mathrm{~min}$ (orlistat $1.94(\mathrm{SEM} 0.15) \mathrm{g} / 100 \mathrm{ml} \times \min v$. control $1.86($ SEM 0.19$) \mathrm{g} / 100 \mathrm{ml} \times \mathrm{min}$ and -5 to $240 \mathrm{~min}$ (orlistat $4.30(\operatorname{SEM~} 0.32) \mathrm{g} / 100 \mathrm{ml} \times \min v$. control $4.22($ SEM 0.40$)$ $\mathrm{g} / 100 \mathrm{ml} \times \mathrm{min})$.

There was no significant difference in the baseline (i.e. $\mathrm{t}-5 \mathrm{~min}$ ) blood glucose concentration between the two study days. Blood glucose increased $(P<0.05)$ after the drink on both days (Fig. 1(c)). The magnitude of the rise from baseline was greater at both $15 \mathrm{~min}$ (orlistat 1.07 (SEM 0.2) $\mathrm{mmol} / \mathrm{l} v$. control $0.75(\operatorname{SEM~} 0.2) \mathrm{mmol} / \mathrm{l} ; P=0.05$ ) and at $30 \mathrm{~min}$ (orlistat 1.06 (SEM $0 \cdot 1$ ) mmol/l $v$. control 0.51 (SEM 0.3 ) $\mathrm{mmol} / \mathrm{l} ; P=0.001$ ) after orlistat. There was no overall difference in the rise from baseline $(P=0.31)$ or peak blood glucose (orlistat 6.87 (SEM 0.17 ) $\mathrm{mmol} / \mathrm{l} v$. control 6.97 (SEM 0.28$) \mathrm{mmol} / \mathrm{l}$ ) between the $2 \mathrm{~d}$ (Fig. 1(c)). There was also no significant difference between orlistat and control in the AUC between -5 to 30 min (orlistat $22.83(\mathrm{SEM} 3.87) \mathrm{mmol} / \mathrm{l} \times$ min $v$. control $12.90($ SEM 4.56$)$ $\mathrm{mmol} / \mathrm{l} \times \mathrm{min}$ ), -5 to $60 \mathrm{~min}$ (orlistat 37.90 (SEM 3.39) $\mathrm{mmol} /$ $1 \times \min v$. control $17.85(\operatorname{SEM} 11.70) \mathrm{mmol} / 1 \times \min )$ and -5 to $240 \mathrm{~min}$ (orlistat $31.83(\mathrm{SEM} 13.04) \mathrm{mmol} / 1 \times \min v$. control $-18.53($ SEM 39.70$) \mathrm{mmol} / \mathrm{l} \times \mathrm{min})$.

\section{Relationships between plasma alcohol and blood glucose concentrations and gastric emptying}

There was a significant inverse relationship between plasma alcohol concentrations and the $50 \%$ gastric emptying time in the total group; for example, at $\mathrm{t} 30 \mathrm{~min}(r-0.65$; $P=0.002$ ), which was not significant in the orlistat $(r-0.57 ; P=0.08)$, but significant in the control $(r-0.65$; $P=0 \cdot 02$ ), group (Fig. 2(a)). There was a significant inverse relationship between the blood glucose concentration and gastric emptying in the total group; for example, at $\mathrm{t} 15 \mathrm{~min}$
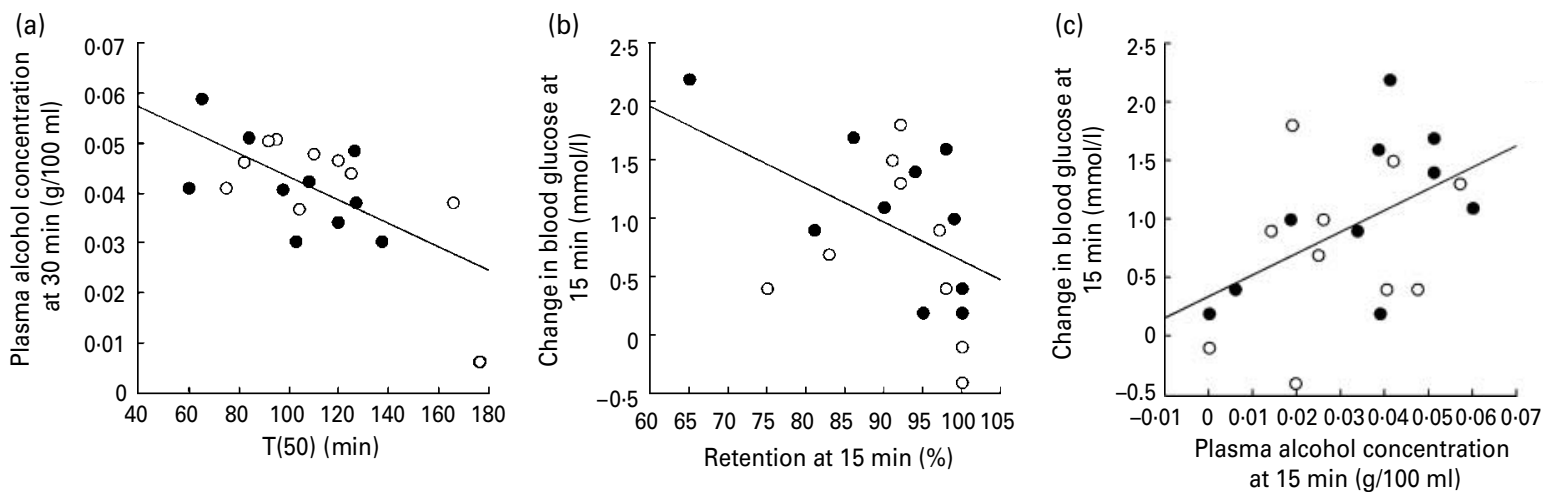

Fig. 2. Relationships between (a) plasma alcohol concentrations at $30 \mathrm{~min}$ and the $50 \%$ emptying time (T50) for gastric emptying $(r-0.65$; $P=0.002)$, (b) the rise in blood glucose from baseline and the intragastric retention at $15 \mathrm{~min}(r-0.46 ; P=0.04)$ and $(\mathrm{c})$ the plasma alcohol concentration at $15 \mathrm{~min}$ and the rise in blood glucose from baseline at $15 \mathrm{~min}(r 0.49 ; P=0.03)$ in the total group. $(\bullet)$, Orlistat; $(O)$, control. For details of subjects and procedures, see p. 884 . 
( $r-0.46 ; P=0.04)$, which was significant in the orlistat $(r-0.66 ; P=0.03)$, but not the control $(r-0.24 ; P=0.3)$ group (Fig. 2(b)). There was a direct relationship between blood glucose and plasma alcohol concentrations in the total group; for example, at t $15 \min (r 0.49 ; P=0.03)$, which was not significant in the orlistat $(r 0.61 ; P=0.06)$ or control $(r 0 \cdot 34 ; P=0 \cdot 34)$, groups (Fig. 2(c)).

\section{Discussion}

Orlistat is a potent inhibitor of lipase in the gastrointestinal tract (Borgstrom, 1988; Drent \& van der Veen, 1993; O'Donovan et al. 2004a) and is used widely in the management of obesity. The present study demonstrates that in healthy male subjects the incorporation of orlistat into a cream 'preload' accelerates gastric emptying of an alcoholcontaining drink consumed $30 \mathrm{~min}$ later, and this is associated with an initially greater blood alcohol and glycaemic response, although these effects were all relatively modest and unlikely to be of clinical significance. Both alcohol absorption and postprandial glucose concentrations were shown to be dependent on the rate of gastric emptying, as has been noted previously (Horowitz et al. 1989; Rayner et al. 2001). Moreover, the magnitude of the elevation in blood alcohol and glucose were shown to be related, which, while not unexpected, has not to our knowledge been demonstrated previously.

Melia et al. (1998) reported that short-term treatment with orlistat had no effect on alcohol absorption after a drink containing $13.9 \mathrm{~g}$ carbohydrate and $41.7 \mathrm{~g}$ alcohol, which is not surprising, given the absence of fat (Melia et al. 1998). It has been well established that gastric emptying of carbohydrate has a major influence on postprandial glycaemia accounting for about $35 \%$ of the variance in the initial blood glucose response to $75 \mathrm{~g}$ oral glucose loads in cross-sectional studies of healthy subjects (Horowitz et al. 1993a) and patients with type 2 diabetes (Jones et al. 1996). In our present study, subjects consumed a high-fat 'preload' before a drink that predominantly comprised carbohydrate, since the effects of fat to slow gastric emptying were likely to be more marked than if the fat was included in the drink (Welch et al. 1987; Cunningham \& Read, 1989). If it is assumed that the cream emptied from the stomach at a rate of about $12.6 \mathrm{~kJ} / \mathrm{min}$ ( $3 \mathrm{kcal} / \mathrm{min}$ ) (Edelbroek et al. 1993), some $25 \%$ should have entered the small intestine at the time of ingestion of the drink. The presence of digested and digestible fat in the small intestine would be expected to slow gastric emptying of the drink (Stacher et al. 1991). The observed relationships between both plasma alcohol and blood glucose responses with gastric emptying are consistent with previous reports (Nimmo, 1976; Holt, 1981; Horowitz et al. 1993a; Jones et al. 1996), which have established that the latter is evident even after low carbohydrate loads (O'Donovan et al. 2004b; Chaikomin et al. 2005). It should be acknowledged that the present study was not specifically designed to evaluate relationships. It is therefore not surprising that correlations were more evident in the total group ( $n$ 20) rather than in the individual groups $(n 10)$.

The magnitude of the acceleration of gastric emptying by orlistat was small, as reflected in the blood alcohol and glucose responses. There are a number of possible explanations for this. The acceleration of gastric emptying by orlistat may potentially have been more marked if the fat were consumed as a liquid emulsion (Schwizer et al. 1997) and if the fat content of the alcohol-containing drink had been higher, given that the effects of lipase inhibition on gastric emptying are dependent on the fat load (Schwizer et al. 1997; Borovicka et al. 2000). As our subjects were studied in the sitting position it is possible that, because of its lower density, ingestion of the drink would result in 'layering' of some, or all, of the remaining intragastric fat (Horowitz et al. 1993b); if so, the carbohydrate would empty preferentially and, thereby, regulate gastric emptying. While the orlistat was mixed thoroughly into the cream, the latter is a stabilised droplet emulsion of fat in which protein encases the fat droplets, and may have limited access of orlistat to the fat surface.

Had the differences in gastric emptying been more pronounced we would have expected higher initial postprandial rises in both plasma alcohol and blood glucose concentrations (as we have shown previously in patients with type 2 diabetes (Pilichiewicz et al. 2003; O'Donovan et al. 2004a)), which may have significant implications for driving a motor vehicle or operating machinery, and for glycaemic control in patients with diabetes. This is of major relevance to patients with diabetes given that postprandial glycaemia affects glycated $\mathrm{Hb}$ (Bastyr et al. 2000) and may also be an independent risk factor for macrovascular disease (Saydah et al. 2001; Del Prato, 2002).

It could be expected that in patients with delayed gastric emptying, the potential effects of orlistat on gastric emptying, blood alcohol and postprandial glycaemia may be reduced; however, this has not been previously studied.

Because of the potential limitations to the present study the provisional conclusion that orlistat does not have any meaningful effect on alcohol absorption in healthy subjects should be treated circumspectly.

\section{Acknowledgements}

The present study was supported by the National Health and Medical Research Council (NH\&MRC) of Australia. Dr Chaikomin's salary is provided by a scholarship from the Thai Government and the Faculty of Medicine, Siriraj Hospital, Mahidol University, Bangkok, Thailand. Dr Jones's salary is funded jointly by Diabetes Australia and the NH\&MRC of Australia. Dr Feinle-Bisset's salary is supported by a Career Development Award from the NH\&MRC of Australia. The authors wish to thank staff of the Department of Nuclear Medicine, Positron Emission Tomography and Bone Densitometry, Royal Adelaide Hospital for providing radiopharmaceuticals and gamma camera time.

\section{References}

Bastyr EJ III, Stuart CA, Brodows RG, Schwartz S, Graf CJ, Zagar A \& Robertson KE (2000) Therapy focused on lowering postprandial glucose, not fasting glucose, may be superior for lowering HbA1c. IOEZ Study Group. Diabetes Care 23, 1236-1241.

Borgstrom B (1988) Mode of action of tetrahydrolipstatin: a derivative of the naturally occurring lipase inhibitor lipstatin. Biochim Biophys Acta 962, 308-316.

Borovicka J, Schwizer W, Guttmann G, Hartmann D, Kosinski M, Wastiel C, Bischof-Delaloye A \& Fried M (2000) Role of lipase 
in the regulation of postprandial gastric acid secretion and emptying of fat in humans: a study with orlistat, a highly specific lipase inhibitor. Gut 46, 774-781.

Caballeria J, Frezza M, Hernandez-Munoz R, DiPadova C, Korsten MA, Baraona E \& Lieber CS (1989) Gastric origin of the first-pass metabolism of ethanol in humans: effect of gastrectomy. Gastroenterology 97, 1205-1209.

Carney BI, Jones KL, Horowitz M, Sun WM, Penagini R \& Meyer JH (1995) Gastric emptying of oil and aqueous meal components in pancreatic insufficiency: effects of posture and on appetite. Am J Physiol 268, G925-G932.

Chaikomin R, Doran S, Jones KL, Feinle-Bisset C, O'Donovan D, Rayner CK \& Horowitz M (2005) Initially more rapid small intestinal glucose delivery increases plasma insulin, GIP, and GLP-1 but does not improve overall glycemia in healthy subjects. Am J Physiol 289, E504-E507.

Collins PJ, Horowitz M, Cook DJ, Harding PE \& Shearman DJ (1983) Gastric emptying in normal subjects - a reproducible technique using a single scintillation camera and computer system. Gut 24, 1117-1125.

Cooper JD (1971) Determination of blood ethanol by gas chromatography. Clin Chim Acta 33, 483-485.

Cunningham KM \& Read NW (1989) The effect of incorporating fat into different components of a meal on gastric emptying and postprandial blood glucose and insulin responses. Br J Nutr 61, $285-290$.

Davidson MH, Hauptman J, DiGirolamo M, et al. (1999) Weight control and risk factor reduction in obese subjects treated for 2 years with orlistat: a randomized controlled trial. JAMA 281, $235-242$.

Del Prato S (2002) In search of normoglycaemia in diabetes: controlling postprandial glucose. Int $J$ Obes Relat Metab Disord 26, Suppl. 3, S9-S17.

DiPadova C, Worner TM, Julkunen RJ \& Lieber CS (1987) Effects of fasting and chronic alcohol consumption on the first-pass metabolism of ethanol. Gastroenterology 92, 1169-1173.

Drent ML \& van der Veen EA (1993) Lipase inhibition: a novel concept in the treatment of obesity. Int J Obes Relat Metab Disord 17, $241-244$

Edelbroek MA, Horowitz M, Wishart JM \& Akkermans LM (1993) Effects of erythromycin on gastric emptying, alcohol absorption and small intestinal transit in normal subjects. J Nucl Med 34, $582-588$.

Feinle C, O'Donovan D, Doran S, Andrews JM, Wishart J, Chapman I \& Horowitz M (2003) Effects of fat digestion on appetite, APD motility, and gut hormones in response to duodenal fat infusion in humans. Am J Physiol 284, G798-G807.

Frezza M, di Padova C, Pozzato G, Terpin M, Baraona E \& Lieber CS (1990) High blood alcohol levels in women. The role of decreased gastric alcohol dehydrogenase activity and first-pass metabolism. N Engl J Med 322, 95-99.

Hebbard GS, Sun WM, Bochner F \& Horowitz M (1995) Pharmacokinetic considerations in gastrointestinal motor disorders. Clin Pharmacokinet 28, 41-66.

Holt S (1981) Observations on the relation between alcohol absorption and the rate of gastric emptying. Can Med Assoc J 124, 267-277, 297.

Horowitz M, Cunningham KM, Wishart JM, Jones KL \& Read NW (1996) The effect of short-term dietary supplementation with glucose on gastric emptying of glucose and fructose and oral glucose tolerance in normal subjects. Diabetologia 39, 481-486.

Horowitz M, Edelbroek MA, Wishart JM \& Straathof JW (1993a) Relationship between oral glucose tolerance and gastric emptying in normal healthy subjects. Diabetologia 36, 857-862.
Horowitz M, Jones K, Edelbroek MA, Smout AJ \& Read NW (1993b) The effect of posture on gastric emptying and intragastric distribution of oil and aqueous meal components and appetite. Gastroenterology 105, 382-390.

Horowitz M, Maddox A, Bochner M, Wishart J, Bratasiuk R, Collins P \& Shearman D (1989) Relationships between gastric emptying of solid and caloric liquid meals and alcohol absorption. Am J Physiol 257, G291-G298.

Hunt JN, Smith JL \& Jiang CL (1985) Effect of meal volume and energy density on the gastric emptying of carbohydrates. Gastroenterology 89, 1326-1330.

Johnson RD, Horowitz M, Maddox AF, Wishart JM \& Shearman DJ (1991) Cigarette smoking and rate of gastric emptying: effect on alcohol absorption. BMJ 302, 20-23.

Jones KL, Horowitz M, Carney BI, Wishart JM, Guha S \& Green L (1996) Gastric emptying in early noninsulin-dependent diabetes mellitus. J Nucl Med 37, 1643-1648.

Lin HC, Doty JE, Reedy TJ \& Meyer JH (1989) Inhibition of gastric emptying by glucose depends on length of intestine exposed to nutrient. Am J Physiol 256, G404-G411.

Lin HC, Zhao XT \& Wang L (1996) Fat absorption is not complete by midgut but is dependent on load of fat. Am J Physiol 271, G62-G67.

Melia AT, Zhi J, Zelasko R, Hartmann D, Guzelhan C, Guerciolini R \& Odink J (1998) The interaction of the lipase inhibitor orlistat with ethanol in healthy volunteers. Eur J Clin Pharmacol 54, 773-777.

Nimmo WS (1976) Drugs, diseases and altered gastric emptying. Clin Pharmacokinet 1, 189-203.

O’Donovan D, Horowitz M, Russo A, Feinle-Bisset C, Murolo N, Gentilcore D, Wishart JM, Morris HA \& Jones KL (2004a) Effects of lipase inhibition on gastric emptying of, and on the glycaemic, insulin and cardiovascular responses to, a high-fat/carbohydrate meal in type 2 diabetes. Diabetologia 47, 2208-2214.

O'Donovan DG, Doran S, Feinle-Bisset C, Jones KL, Meyer JH, Wishart JM, Morris HA \& Horowitz M (2004b) Effect of variations in small intestinal glucose delivery on plasma glucose, insulin, and incretin hormones in healthy subjects and type 2 diabetes. J Clin Endocrinol Metab 89, 3431-3435.

Pilichiewicz A, O’Donovan D, Feinle C, Lei Y, Wishart JM, Bryant L, Meyer JH, Horowitz M \& Jones KL (2003) Effect of lipase inhibition on gastric emptying of, and the glycemic and incretin responses to, an oil/aqueous drink in type 2 diabetes mellitus. J Clin Endocrinol Metab 88, 3829-3834.

Rayner CK, Samsom M, Jones KL \& Horowitz M (2001) Relationships of upper gastrointestinal motor and sensory function with glycemic control. Diabetes Care 24, 371-381.

Saydah SH, Miret M, Sung J, Varas C, Gause D \& Brancati FL (2001) Postchallenge hyperglycemia and mortality in a national sample of U.S. adults. Diabetes Care 24, 1397-1402.

Schwizer W, Asal K, Kreiss C, Mettraux C, Borovicka J, Remy B, Guzelhan C, Hartmann D \& Fried M (1997) Role of lipase in the regulation of upper gastrointestinal function in humans. Am J Physiol 273, G612-G620.

Stacher G, Bergmann H, Gaupmann G, Schneider C, Kugi A, Hobart J, Binder A \& Mittelbach-Steiner G (1990) Fat preload delays gastric emptying: reversal by cisapride. $\mathrm{Br}$ J Clin Pharmacol 30, 839-845.

Stacher G, Granser GV, Bergmann H, Kugi A, Stacher-Janotta G \& Hobart J (1991) Slow gastric emptying induced by high fat content of meal accelerated by cisapride administered rectally. Dig Dis Sci 36, 1259-1265.

Welch IM, Bruce C, Hill SE \& Read NW (1987) Duodenal and ileal lipid suppresses postprandial blood glucose and insulin responses in man: possible implications for the dietary management of diabetes mellitus. Clin Sci (Lond) 72, 209-216. 